Given the book's subtitle, such an inexhaustive approach is disappointing but perhaps inevitable as we know already there are not enough health economics studies to fill a whole book. Nevertheless, this is a good compendium of research and is generally up to date. The discussions have a strong US bias, but unlike many books of this type there is a reasonable coverage of non-American studies. The emphasis on diagnosis, however, limits the book too much, although a good chapter on medical conditions mitigates this.

For anyone trying to convince service commissioners that non-drug treatments are effective this book is invaluable. It argues cogently that psychotherapy can be cost-effective, but that is a big step from saying that it always will be, as cost-effectiveness depends crucially on how a service is delivered.
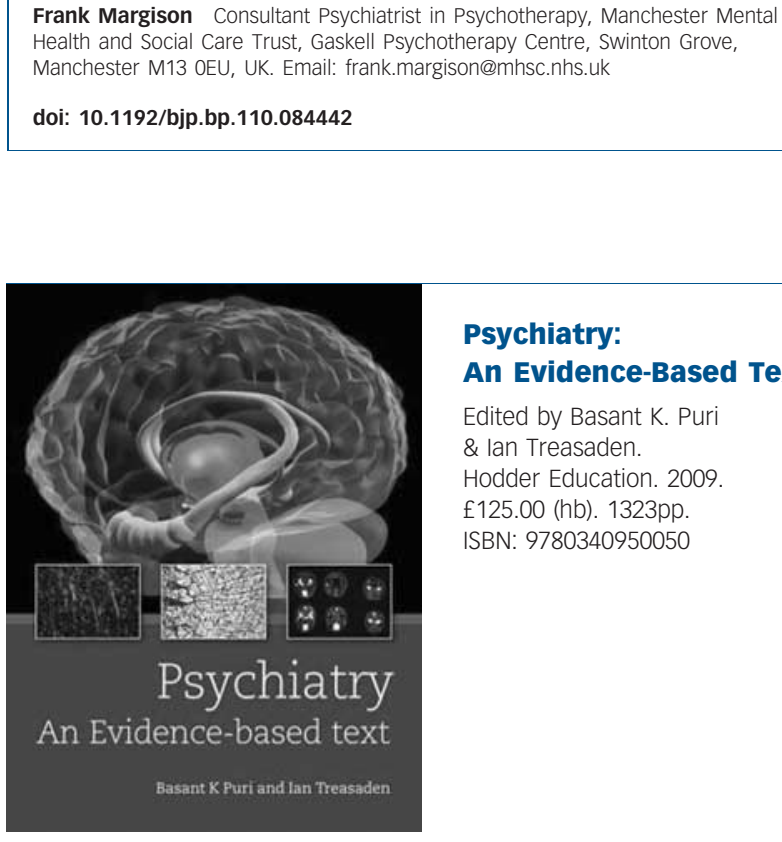

\section{Psychiatry: An Evidence-Based Text}

Edited by Basant K. Puri \& Ian Treasaden. Hodder Education. 2009 f125.00 (hb). 1323pp. ISBN: 9780340950050

This is the newest addition to the standard texts for trainees preparing for the MRCPsych examination in the UK and Ireland. The breadth of topics covered is impressive and includes a history of psychiatry, basic psychology, statistics, neurosciences (including neuroimaging and anatomy), mental disorders, and medical and psychological management. The book touches on clinical specialties, management of mental health services and legal and ethical aspects of psychiatry, as well as subjects infrequently covered in other texts: emergency psychiatry, chronic pain and palliative care. Some of the chapters are supplemented with a reading list.

The book makes abundant use of tables, images and summary boxes. The sections on basic psychology and psychological therapies are likely to be sufficient for those preparing for the MRCPsych exam. This may sweeten the pill of the hefty price tag and obviate the need for additional textbooks. In the chapters covering mental illness, common pathologies are covered alongside the less common ones: psychosexual disorders and paraphilia. The sections on functional disorders are extensive and, rather perturbingly, the chapter on multiple chemical sensitivities is considerably longer than the one on schizophrenia. The ICD-10 and DSM-IV criteria are provided for some disorders but omitted in others. This may prove frustrating to those preparing for exams who wish to have all the relevant information to hand.
Despite these few shortcomings, this book will provide a solid reference source which can confidently take its place next to its more established rivals.

Floriana Coccia Birmingham and Solihull Mental Health NHS Foundation Trust, The Barberry Centre, 25 Vincent Drive, Birmingham B15 2FG, UK.

Email: floriana.coccia@yahoo.co.uk

doi: 10.1192/bjp.bp.110.080200

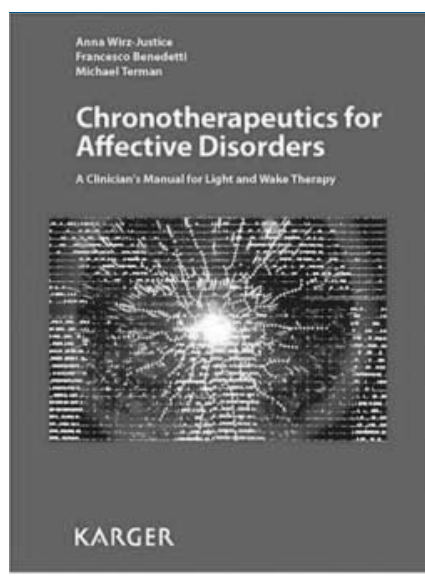

\section{Chronotherapeutics} for Affective Disorders: A Clinician's Manual for Light and Wake Therapy

By Anna Wirz-Justice, Francesco Benedetti \& Michael Terman. Karger. 2009. US\$48.00 (pb). $116 \mathrm{pp}$. ISBN: 9783805591201

This book has three stated aims. The authors present the theory behind chronobiological treatments for affective disorder, document evidence of their efficacy and provide a step-by-step guide to clinicians as to how these therapies might be implemented. My main criticism of the book is that the balance between these three areas may not be optimal.

Manuals should probably instruct readers in how to do something rather than explain in depth why they should do it. However, whereas the guide to the implementation of chronotherapeutic techniques is detailed, the theory underlying these techniques merits expansion and I felt that evidence for their effectiveness was significantly lacking. For example, the efficacy of bright light treatment for non-seasonal depression is affirmed in fewer than 100 words, with only two references. In some European countries, chronotherapeutics are quite widely used and in Milan it is apparently routine for in-patients on medication for non-seasonal depression to receive light therapy and a single session of late-night wake therapy at the start of treatment. By contrast, in the UK, the authors would be preaching chronotherapeutics to the unconverted; most psychiatric professionals will need to know why they are using a treatment, not least because they might be asked by the patient.

Despite these criticisms, I found the book to be useful and engaging. It is well written and elegantly illustrated and it links to an informative website (www.cet.org) for the Center for Environmental Therapeutics, a non-profit agency dedicated to education and research in environmental therapies. The difficulties inherent in researching and promoting such therapies, in contrast to the international resources of the pharmaceutical industry, are noteworthy.

Most psychiatrists will have patients with unipolar or bipolar depression who are resistant to other treatments and this book may help to see them, literally, in a different light. There is a very useful level of detail about light therapy, including ways of estimating the best time of day at which it can be prescribed, since this varies between individuals. Helpful illustrative schedules are 
given for using light therapy alone, wake therapy plus light therapy and wake therapy plus light therapy plus sleep phase advance. There are informative sections on the use of melatonin and the practicalities of light therapy, including recognition that motivated and knowledgeable night nurses are required to competently implement some of the chronotherapeutic techniques with in-patients.

Overall, I feel that clinicians who work with patients with affective disorders should gain new and significant insights from reading this book.

John M. Eagles Consultant Psychiatrist, Royal Cornhill Hospital, Cornhill Road, Aberdeen AB25 2ZH, UK. Email: john.eagles@nhs.net

doi: $10.1192 /$ bjp.bp. 110.080176

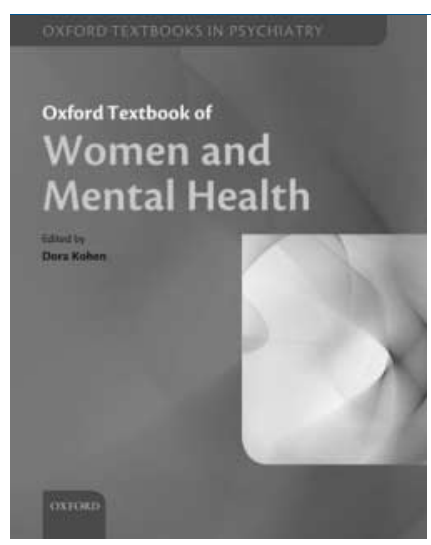

\section{Oxford Textbook of Women and Mental Health}

Edited by Dora Kohen. Oxford University Press. 2010 f75.00 (pb). 352pp. ISBN: 9780199214365

I wanted to like this book; I knew and respected Professor Kohen although I did not always agree with her. Healthy debate has, however, always formed an important part of the Royal College of Psychiatrists' Women in Psychiatry Special Interest Group, to which Professor Kohen brought her extensive intellect and unique perspective.

The book is advertised by the publisher as including chapters by leading experts in their respective fields providing 'the most authoritative information available'. There are contributions from academics in Canada, England, India, Ireland, Switzerland and Turkey. Some are indeed leading experts; however, others are not and despite their best efforts in some chapters this shows.

Although I enjoyed reading many of the chapters, I found the overall structure of the book rather confused. Part 1 focuses on 'Fundamental aspects: women and mental health'. This was an enjoyable section covering issues such as stigma, violence and ethnicity. I was pleased to see a chapter on lesbianism and mental health, an area much neglected in contemporary research despite the health inequalities experienced by lesbians. I particularly enjoyed the useful introduction to biological sex differences relating to mental health, but was disappointed that this was not followed up with specific coverage of gender differences in prescribing (although this was actively considered in the section on intellectual disability later in the book).

I found Part 2, 'Clinical aspects: women and mental health', less coherent. Under the heading of mental illness a number of disorders such as anxiety, depression, borderline personality disorder and schizophrenia are considered, yet post-traumatic stress disorder is not; this was addressed as a 'special clinical topic' in Part 3. There is a specific section on perinatal psychiatric disorders and, importantly, parental psychiatric disorders are also considered. Specific focus is also given to substance misuse, eating disorders and women with intellectual disabilities. I was surprised not to find a section on the mental health difficulties and challenges faced by older women.

I support the arguments of this book; it highlights, from a multidisciplinary perspective, some of the essential issues facing women in the context of their daily lives and how these issues relate to their mental health. I welcome an approach that considers women's different roles as carers, parents, workers and partners. Overall the chapters were succinct, well written and comprehensive. I accept that no book can cover all areas of such a broad topic, but in parts the coverage was lacking. If you expect a 'practical' text focused on service delivery, then you will be disappointed but if you accept that this is not a practical guide, then this book is a noteworthy addition to the literature.

Fiona L. Mason Consultant Forensic Psychiatrist and Deputy Medical Director,

St Andrew's Healthcare, Billing Road, Northampton NN1 5DG, UK.

Email: fmason@standrew.co.uk

doi: 10.1192/bjp.bp. 110.082628

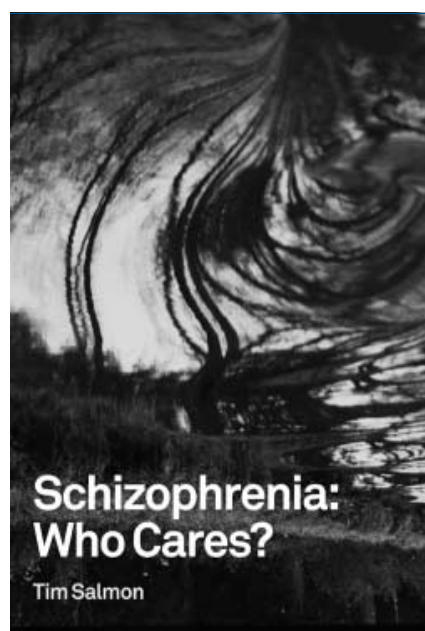

\section{Schizophrenia:} Who Cares?

By Tim Salmon Artaxerxes Press. 2010 £12.00 (pb). 178pp. ISBN: 9780956507006

I found this book to be a bit of a long gripe at times, but nonetheless a salutary one. Before embarking on it I kept in mind three questions: Will it provide comfort/advice/guidance to other carers? Will it make mental health professionals more aware of the plight of the carer? Will it offer insights on what carers actually need in terms of support? The answer to all three questions is yes, in parts.

The book relates a 20-year history of a father not only struggling to come to terms with his son's schizophrenia, prompting guilty, soul-searching questions, but also having to cope with the idiosyncrasies of the caring system, which apparently often failed both him and his son. Father deserves admiration for the courage, resilience and sheer utter resolve not to abandon a son in distress, even when he behaved in an appalling, bewildering and risky manner, living between the extremes of 'constant worry, increasing anxiety and heart-inmouth horror'. Salmon describes the incomprehensible institutional routines, the Kafkaesque bureaucratic system, constant changes in policy and personnel, and the impersonal system of care', which fails to take into account the inability of a person with a mental illness to navigate its forms and procedures, constantly fails to deliver despite good intentions and high-sounding but empty rhetorical words (consultation, empowerment, normalisation, accessibility, flexible pathways, 